\title{
"Fight Like a Girl": Tattoos as Identity Constructions for Women Living with Illness
}

\author{
${ }^{1}$ Linguistics and English Language, Lanacster University, Lancaster, United Kingdom of Great Britain and Northern Ireland, \\ E-mail: v.koller@lancaster.ac.uk \\ ${ }^{2}$ Manchester Metropolitan University, Manchester, United Kingdom of Great Britain and Northern Ireland
}

\begin{abstract}
:
In this article, we explore the functions that tattoos worn by women with breast cancer or endometriosis have in constructing identities for the wearer and conceptualise the respective illness. Drawing on previous literature on multimodal communication, tattoos and illness, we analyse a sample of 59 different tattoos for their ideational function in constructing identities. A social semiotic analysis shows that lexemes, images, type fonts and intertextuality work together to construct dominant identities for the women wearing the tattoos: as a fighter or warrior, or as a sufferer. The first, metaphoric, identity shows hybrid gendering and constructs the illness as an adversary, while the identity as sufferer often has religious overtones, particularly for breast cancer tattoos. Subversive identities centre on despair or rationality, and as such constitute an alternative to social imperatives of either staying strong and fighting the illness or accepting one's fate. We close by discussing in how far the tattoos do justice to the complexity of living with an illness and how our research shows the need to include visual stimuli in medical consultations.
\end{abstract}

Keywords: tattoos, breast cancer, endometriosis, identity construction

DOI: $10.1515 / \mathrm{mc}-2018-0006$

\section{Introduction}

In this paper, we will show how illness-related tattoos worn by women with breast cancer or endometriosis serve to construct identities for both the disease, which is seen as an enemy or a burden, and for the woman living with the disease, who positions herself as a fighter or as a sufferer. Our aim is therefore to shed light on the experiential (also known as ideational) function of tattoos, i. e. how they serve to convey the experiences of women with breast cancer or endometriosis, and what identities and views of the diseases the women have adopted as a result. It has been noted that tattoos act as 'vehicles for self-expression, commemoration, community building, and social commentary' (Kang and Jones 2007: 47) and thus also have an interpersonal function. Indeed, the very act of wearing an illness-related tattoo - as long as it is not covered by clothing - helps to make breast cancer and endometriosis visible and thereby enables the wearer to connect with others living with the respective disease. Two endometriosis tattoos (ED17, ED18) ${ }^{1}$ incorporate the very word 'visible' to refer to this interpersonal function. In addition, photographs of tattoos are often posted on social media (see below on data collection), along with hashtags and account handles such as \#endosisters or @breastfriends. The practice of posting and the hashtags and account handles foster a sense of community, as evidenced by solidarity and appreciation as the main reactions to the act of posting, e. g. in comments such as 'my new tattoo' - 'Ohhhhh I love it !!:'. This echoes DeMello's (2000) view that tattoos allow members of a subculture to feel that they have found others like themselves. In this study, however, we reserve our attention for how tattoos allow wearers to construct identities for their illness and for themselves through multimodal imprints on their bodies. As we will discuss throughout the analysis, we see the identity-constructing functions of the tattoos in our data as reflections of macro-level discourses on femininity and on living with an illness.

We decided to focus on the tattoos worn by women with breast cancer or endometriosis because both conditions are widespread but otherwise differ in their nature and in the level of public awareness. Breast cancer is the most common cancer in England: of the 303,135 cases of cancer registered in 2016, breast cancer accounted for $15.2 \%$, of which $99.3 \%$ affected women (Office for National Statistics 2018). The frequency of this type of cancer has translated into a high level of public awareness; in England and Wales alone, there are 65 charities dedicated to breast cancer, albeit different in their aims and scope (Charity Commission n.d.). Furthermore, October has been Breast Cancer Awareness month in the UK, the US and many other countries since 1985 and now features many high profile events (next to a hefty dose of commercialisation, see King 2006). Such public 
awareness, together with fundraising, has meant that there has been substantial research into the treatment, if not causes, of breast cancer. The illness now has one of the best survival rates of all cancers, with almost 90 out of every 100 women still alive five years after diagnosis (Cancer Research UK 2017). By contrast, endometriosis, which affects an estimated 2 million women in the UK, is a very different condition. While not fatal, it is a debilitating gynaecological disease causing incapacitating pain and other intimate and hence often taboo symptoms. It accounts for $50 \%$ of all cases of infertility in the UK (Endometriosis UK n.d.). Despite affecting one in ten women, endometriosis symptoms are often normalised as a part of the female condition and it is usually only diagnosed as a result of investigating infertility, rather than following complaints about incapacitating and life-altering pain and associated symptoms (Arruda et al. 2003). Indeed, worldwide it takes an average 7.5 years for the condition to be diagnosed.The difficulty in articulating the symptoms of the disease, its lack of visible manifestations and the perceived taboo of discussing its effects contribute to a feeling of disempowerment, alienation and invisibility (e. g. Culley et al. 2013; De Graaff et al. 2013).

Despite these differences between breast cancer and endometriosis, the tattoos worn by women with the respective disease are remarkably similar in function, suggesting a wider socio-cultural phenomenon worth investigating. To do so, we have formulated the following research questions:

How do the visual and linguistic features in illness-related tattoos construct identities for women living with breast cancer or endometriosis? What identities do those features construct for those medical conditions?

To answer these questions, we will in the next section review the literature on illness, multimodal communication and tattoos. We define multimodal communication as the use of signs combining linguistic and other (here: visual) modes to make meaning in social contexts. Using tools from systemic functional-multimodal discourse analysis (e. g. O'Halloran 2008), we analyse the experiential (ideational) meaning of tattoos as multimodal artefacts that integrate various semiotic resources. We pose that tattoos, as multimodal artefacts, concurrently allow the construction of ideational meaning (i. e. representing human experience) and interpersonal meaning (i. e. enacting social relations) enabled through the organisation of the discourse, i. e. the textual function of semiosis (e. g. Halliday 1978; Kress and van Leeuwen 2006). As mentioned above, however, our focus for this paper will be on the experiential or ideational meaning afforded by tattoos.

Following our overview of the relevant literature, we will introduce our data and provide detail on how we collected, prepared and analysed them. The analysis itself is structured in line with our findings about what identities the tattoos construct for women living with illness. We will discuss how lexemes, images and intertextuality - i. e. the integration of parts of one text into another (Fairclough 2003: 40), the dialogue between texts (Kristeva and Moi 1986) - are combined in the tattoos to construct identities as a fighter or a sufferer for the wearer of the tattoo. As the identity of the woman wearing the tattoo is inextricably linked to the identity of the condition itself, we also elaborate on how the same features construct the diseases as an enemy or a burden. As we shall see, dominant identities contrast with more subversive ones centring around despair or rationality. Throughout the analysis, we also look at how these different identities are feminised through the use of type fonts, colour and images. Additional evidence is provided by looking at the identity-building functions that the wearers report the tattoos to have for them. To conclude the paper, we will problematise the identities constructed by the tattoos and point out areas for further research.

First however, we will turn to how the links between illness, multimodal communication and tattoos have been discussed in the literature to date.

\section{Illness, multimodal communication and tattoos}

In the following, we first discuss previous research on how illness can be communicated visually and multimodally. We then discuss tattoos as multimodal artefacts and finally bring the different strands together by outlining the role of tattoos with regard to illness.

\section{Illness and multimodal communication}

That illnesses and the feelings and practices associated with them can be communicated in various semiotic modes has been a matter of public knowledge for some time now. Trusts and disease support organisations, such as The Breast Cancer Fund et al. (1998), advocate that visual art produced by sufferers gives the latter visibility and a voice. Examples in relation to endometriosis and breast cancer are, respectively, the works of Australian artist Ellie Kammer, and of British photographer Jo Spence and American artist Martha Hall. Kammer's paintings, with their bold imagery of endometriosis symptoms, aim to give visibility to the disease and 
challenge taboos around how it is perceived (Darling 2017). Similarly, Spence's photography and Hall's paintings also address the issue of visibility. In an exploration of the work of the two artists, both of whom died of breast cancer after decades of treatment, Bell (2006) discusses that works by artists with illnesses not only educate audiences but also negotiate and transform relations with healthcare by forging links with people around the patient, who are also affected by the condition. In this way, art serves to connect "personal experiences with place, time, and circumstances, helps create support networks, and improve social life" (Bell 2006: 32). Artefacts allow us to see bodies in the way the sick person does and hence make public the private experience of the disease, "resulting in the possibility of a collective outcome" (Radley 2002: 12).

Radley and Bell (2007) argue that artworks produced by people with illnesses, and breast cancer in particular, "play a key role in making visible and collective the ideological issues ... associated with disease regimes" (p. 366) and might lead to the formulation of shared and collective aims in relation to the disease. In this way, disease related artworks provide "emancipatory potential" for people living with illnesses (ibid.). The authors conclude that "artworks relating to illness do not just show how things are but also what should be the focus of concern", thereby inviting action (p. 371). In this sense, images fulfill both an experiential or ideational and an interpersonal function. By sharing their stories in language and art, women with breast cancer and endometriosis not only explore their own bodies, emotions and environment but also use such experiences as a resource for helping and supporting others (Pitts 2004). Similarly, Al Zidjaly (2011), in an exploration of images of disability, argues that visual texts are more than mere artefacts of expression or representation but rather mediated actions with histories and identities contextualised in local contexts and global systems.

Apart from conveying the patient's expression of the disease, art, along with spoken language, is also becoming a tool in medical consultations. Using images co-created by British artist Deborah Padfield and patients with chronic pain, Semino et al. (2017b) have looked at the role of images in the dynamics of pain consultations. Preliminary findings indicate that images help patients to better disclose the emotional impact of pain in their lives than exclusively verbal accounts do. Similarly, images also improve physicians' empathy and rapport with patients. These findings tell us that a discussion of communication practices around illnesses, whether as an expression of courage, frustration, despair or agency, or as a tool to aid medical practice, needs to consider the various semiotic modes which best convey the intended message in accordance with the affordances of each mode.

\section{Tattoos as multimodal artefacts}

Tattoos constitute interesting multimodal artefacts that incorporate various semiotic modes and that have at least in Western cultures ${ }^{2}$ - become increasingly popular over the past two decades. No longer considered a fringe countercultural practice restricted to seamen or prisoners, tattoos are now worn by people of many walks of life. For example, the number of tattoo studios on British high streets increased by $173 \%$ between 2003 and 2013 (The Economist 2014). Despite their new found popularity though, tattoos are hardly a new object of sociological or anthropological inquiry. As early as 1963, Edgerton and Dingman outlined a number of functions that tattoos have in non-Western societies. They found that tattoos were used as ornaments, as religious or magic symbols, as signs of bravery, as indicators of social status and also, and more predominantly, as markers of identity. Despite the less frequent use of tattoos found in Western societies at the time, Edgerton and Dingman (1963) ascertained that tattoos in the USA fulfilled similar functions to those of non-Western societies, with identity construction again being the most prominent one. Identity for the authors is 'those efforts that people make to define and appraise themselves ... it is inextricably bound to the judgments of others and to efforts, by the self, to affect the judgments of those others' (Edgerton and Dingman 1963: 144). Our first research question, on how tattoos construct identities for their wearers, addresses this specific aspect of tattoos.

A more recent socio-anthropological exploration of tattoos (Atkinson 2003: 56-60) outlines three main functions they have: as expressions of social deviance, as artistic practice, and as a form of resistance and practice of identity politics. This echoes early findings of Edgerton and Dingman's (1963) work on the use of tattoos by people who have had their identity challenged or taken away, such as prisoners or people institutionalised due to mental health issues. Such findings suggest that tattoos "must be understood in relation to the nature and history of tattooing itself" (1963: 152), meaning that the practice can be seen as opposing or challenging dominant practices of expressing identities through the body (Langman 2008). As for resistance, an exploration of feminist literature on tattooed female bodies (Dann et al. 2016) concluded that tattoos offer multiple functions, ranging from agency to self-presentation and the freedom to either conform to or resist hegemonic practices of femininity.

Another relevant notion that could be applied to tattoos as multimodal artefacts is that of "frozen actions" (Norris 2004). These are defined as actions performed by social actors, at one time or another, that become frozen in everyday objects or the environment. Such actions have been assigned to ordinary objects by social actors 
and, by converging with practices and discourses, "[allow] us to partially understand how identity is produced and experienced by social actors in everyday life" (Norris and Makboon 2015: 43). Norris and Makboon (2015) theorise objects and artefacts are seen as "parts of modes" that are "durable due to their materiality when compared to other communicative modes such as gaze, gesture, or posture" (Norris and Makboon 2015: 45). By virtue of their permanency in the social actor's environment, the frozen actions embedded in those objects persist, thereby allowing for an identity production that is durable and has a degree of permanence.

The above notions suggest that tattoos "are something we make in order to be in contact with other people, but also to be in contact with ourselves" (Martin 2013: 43). In socio-semiotic terms, tattoos can be said to meet both an interpersonal and an experiential (or ideational) function (Kress and van Leeuwen 2006: 15). Interpersonally, tattoos allow members of a social group a "sense that they have found people who are like them and who are not like everyone else" (DeMello 2000: 21). Experientially, tattoos allow people to express themselves and their experiences through their bodies, serving as "a canvas to record the struggles between conformity and resistance, power and victimization, individualism and group membership" (Kang and Jones 2007: 47). It is this experiential or ideational function that our investigation into the identity-building affordance of illness-related tattoos focuses on.

\section{Tattoos and illness}

In the context of illness, tattoos used to be restricted to a mark on the patient's skin to aid further radiotherapy in cancer treatments (Bell 2006). These days, however, tattoos are more than merely a utilitarian device. Many tattoo artists cater to women recovering from breast cancer, "both to create a new aesthetic for mastectomy scars and to express the devastating effects of the disease" (Kang and Jones 2007: 44). Tattoos constitute a device for identity performance in breast cancer survivors as they allow a shift from an 'agentless self' tattooed for radiation purposes during therapy to an "agentive self who subsequently had a tattoo done over the scar" (Benwell and Stokoe 2006: 139). Breast cancer tattoos allow for "closure" (Hinde 2017) as they constitute a source of pride, a sign of survival and a symbol of courage and strength. While the last function echoes the early work by Edgerton and Dingman (1963), it also suggests that tattoos have become a symbol of physical and emotional empowerment as a result of the illness, rather than a sign of enduring pain. The discussion of our findings will add some nuance to this rather celebratory view of tattoos as worn by cancer patients.

In the next section, we will elaborate on the tattoos that form our data sample and outline what specific features we analysed, and how.

\section{Data and methods}

Our study is based on 60 images of tattoos, which represent a sample from a much larger number. We collected our data using the Google images search engine as well as social media platforms Pinterest and Instagram for the phrases and hashtags 'breast cancer tattoo', 'endo tattoo' and 'endometriosis tattoo'. That search yielded about 1,000 images for each website and platform before a saturation point was reached in that no new or different images came up. We can say little about the demographic of wearers other than that they are overwhelmingly white and female, as evidenced by pictures of the tattoos and the information on the posters given on Pinterest and Instagram.

Given the large amount of potential data, we decided on a qualitative analysis, which started with identifying and naming the component parts of the tattoos, in order to arrive at a descriptive categorisation. A first close reading of the tattoos suggested that the compositional elements and features fall into four categories: lexemes, images, type fonts and intertextuality. Colour is largely restricted to the pink and yellow of the ribbons symbolizing the respective illnesses (see Sjoholm 2016: 199-200 for a history of pink ribbons for breast cancer; Kronfeld 2018 for the origins of the yellow ribbon for endometriosis). Other than that, colour has mainly aesthetic rather than identity-related functions in the tattoos. Where colour does seem relevant, however, we discuss it as a feature of the images.

Lexemes constitute the language components of tattoos and take the form of individual words, phrases and sentences. To categorise and describe the tattoos, we identified the central lexemes; for example, the sentence 'stay strong' featuring in an endometriosis tattoo was grouped as 'strong', while the eponymous 'fight like a girl', which is often found as part of both breast cancer and endometriosis tattoos, would feature as 'fightgirl'. Where linguistic elements of the tattoos comprised different word classes (e. g. 'strength' and 'strong') or words in the same word class but with different denotational meanings (e. g. 'fight' and 'fighter'), we listed both. Three tattoos featured elements in a language other than English, integrating the Chinese character for 'love', the Japanese character for 'strength'3 and the Latin phrase 'semper ad meliora' ('always toward better 
things'), respectively. As we do not consider the use of other languages relevant for our research questions, we grouped the respective examples under the equivalent lexeme in English.

As for images, we identified what concrete objects they depicted, either individually or in combination. Combinations can take the form of either juxtaposing objects, e. g. showing an anchor next to, and partly overlapping with, flowers (BC19, ED19), or of an integrated image, as in Figure 1:

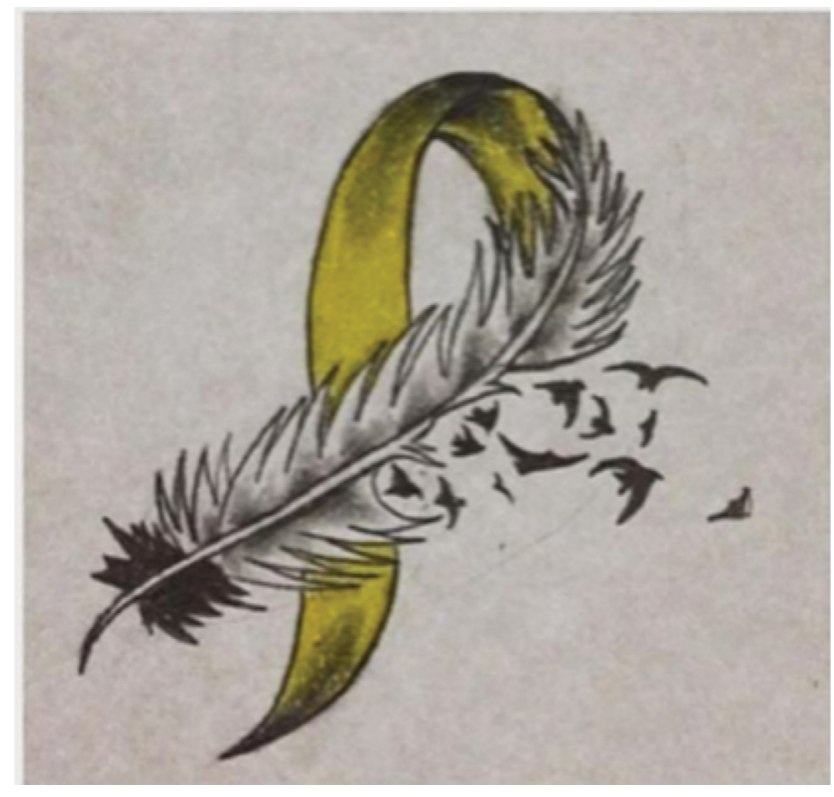

Figure 1: Integrated image in an endometriosis tattoo (ED22).

https://www.instagram.com/p/BKkB_XMhS_m/?utm_source=ig_share_sheet\&igshid=bs1v4mspaxi2

We then related those objects to the lexemes denoting them - for example, the images of a pink ribbon tied around an anchor would be lexicalised as anchor, ribbon - to allow for further descriptive categorisation.

To proceed, type fonts capture the visual aspect of written words and characters. To describe this feature, we drew on those of van Leeuwen's (2006) analytical criteria that were most relevant in the data, namely slope, connectivity and curvature. In the few cases where a tattoo included more than one type font, the one that most words were written in was chosen as the basis for categorisation. ${ }^{4}$ Finally, we also investigated intertextual links, which refer to something outside of the tattoo, by quoting or, in cases of visual intertextuality, re-enacting (Bullo 2014: 49), other texts or images.

The categorisation of elements and features resulted in comprehensive descriptors for the tattoos. Given the predominance of pink or yellow ribbons as a compositional element, we started the descriptor with them; the structure and two examples of descriptors are provided below:

$$
\begin{aligned}
& \text { Ribbon + lexeme(s) + image(s) + type font + intertextuality } \\
& \text { Pink ribbon + 'hope' + butterfly + sloped connected curved (BC12) } \\
& \text { Yellow ribbon + barbed wire, bird, flower (ED21) }
\end{aligned}
$$

In total, we identified 31 descriptors for breast cancer and 29 for endometriosis tattoos (see Table 1 in the Appendix). We selected an example of each of the descriptors, resulting in 60 pictures of tattoos overall. As is clear from the list of descriptors, most tattoos proved to be multimodal, combining one or more images with written text in a particular type font. The descriptive categorisation further showed that only six tattoos in each group share the same descriptors, apart from the colour of the ribbon (see Table 1, shaded lines). However, we shall see in the next section that this formal variety is counterbalanced by functional similarity: while the tattoos feature many different elements and combinations thereof, they for the better part suggest a limited set of identities for the wearers and construct the two diseases in very similar ways. The aim of our analysis is therefore to ascertain what these identity constructions are, and how the multimodal features of the tattoos help to achieve them.

Throughout the analysis, we compare the identities constructed through the tattoos with the identitybuilding functions the wearers themselves report that the tattoos have for them. To facilitate that comparison, we looked at the comments, hashtags and account handles posted alongside Instagram and Pinterest images of tattoos or, in the case of images retrieved from Google Images, the web pages on which they were found. We noted any comments that explicitly stated what identity functions the tattoo had for the wearer, but disregarded 
the interpersonal functions engendered by the practice of posting a picture of the tattoo, such as expressing solidarity or appreciating the tattoos of others.

In the following section, we will discuss how the multimodal elements in the tattoos construct both women living with breast cancer or endometriosis and the disease in question itself.

\section{Identity constructions: analysis of the tattoos}

In this section, we will discuss what and how the tattoos construct identities for their wearers and for the diseases themselves. We will show how the dominant identities of fighters and warriors (and the disease as enemy), or of sufferers (and the disease as burden) sit alongside less prominent, subversive identities centring on despair or rationality.

\section{Fighters and warriors}

Both breast cancer and endometriosis are conceptualised and expressed in metaphoric terms, and as the construction of the disease cannot be separated from the identity of the woman living with it, some identities of the wearers of the tattoos are likewise metaphoric. Given that the context for all the tattoos we collected was illness, lexemes such as 'fight' or 'anchor', and images of boxing gloves or an anchor, can be identified as being used metaphorically, i. e. they have a specific, contextual meaning as part of an illness-related tattoo. The fact that this contextual meaning contrasts with a more basic - more concrete, physical, precise or older - current meaning that the word or image has in other contexts, but can be understood in comparison with it, makes it an instance of metaphor (Pragglejaz Group 2007: 3). In our data, many metaphors are multimodal, with the target domain (i. e. the illness) and the source domain (i. e. what the illness is seen as) being expressed in different modes (Forceville and Urios-Aparisi 2009: 4). Other metaphors in the data are monomodal, i. e. exclusively language-based or exclusively visual.

By far the most prominent metaphors in the tattoos are those of VIOLENCE or WAR, ${ }^{5}$ casting the disease as an aggressor or enemy and the woman living with it as a fighter or warrior. These metaphors have been documented for a variety of physical and mental health conditions (see Flusberg et al. 2018, for an overview), including cancer (e. g. Semino et al. 2017a). In the tattoos, the source domain of violence is represented visually by boxing gloves (BC22, ED11, ED23) and lexically by the words 'fight' (ED6) and 'fighter' (ED9). As shown in research on the metaphors used by cancer patients (Semino et al. 2017a: 61), 'fighter' connotes perseverance and mental strength, which lends a potentially empowering function to many tattoos. This function can be supported visually as well: Figure 2 shows an endometriosis tattoo in which the tattered yellow ribbon is indicative of a metaphorical struggle in which the woman is an agentive self, with signs of fighting the disease being made visible. The wearer's comment 'this won't be the "endo" me' reinforces this fighter identity (while simultaneously introducing an element of humour through the word play).

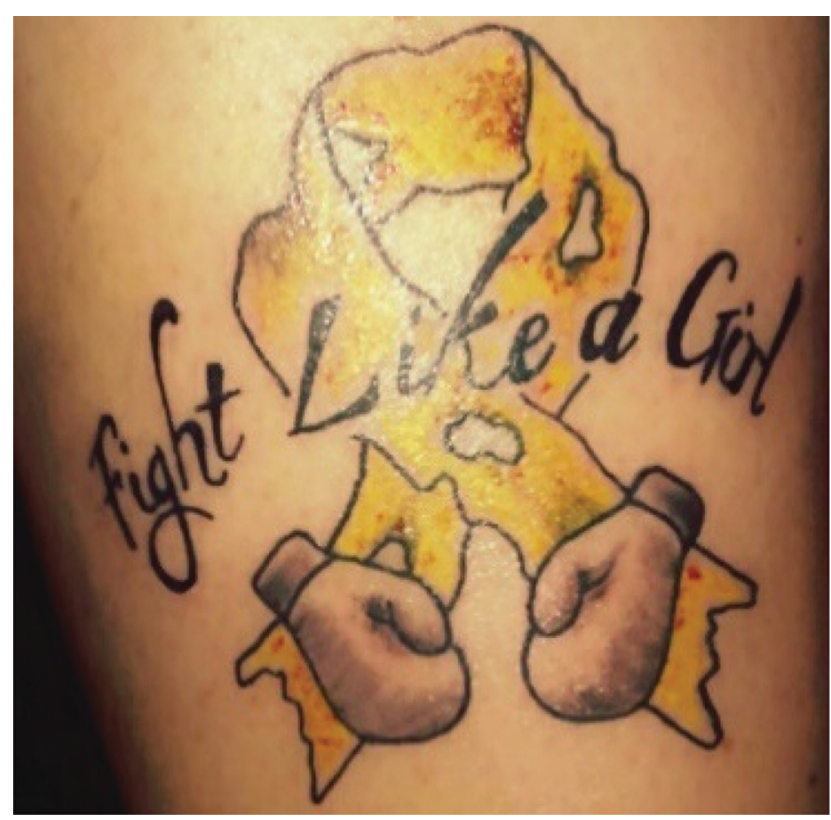


Figure 2: Endometriosis tattoo (ED7).

https: / www.pinterest.com.au/pin/819866307134113683/, accessed 23 November 2017

The more specific domain of war is linguistically expressed by 'battle' (BC4), 'warrior' (ED19) and, arguably, 'hero' (ED2). Such lexemes suggest an identity construction on part of the wearer as aggressive, agentive and positive.

We also find visual representations of the WAR metaphor in tattoos showing military-style dog tags being wound around a pink or yellow ribbon (BC26, ED26). Another visual expression of the WAR metaphor works through intertextuality: the tattoo in question (BC29) re-enacts Joe Rosenthal's famous photograph Raising the Flag on Iwo Jima, taken on February 23, 1945 and depicting six US Marines raising a US flag on top of Mount Suribachi on the Japanese island Iwo Jima, during the Battle of Iwo Jima in WW2. The tattoo represents a similar image of the soldiers raising a flag featuring the breast cancer pink ribbon (Figure 3).

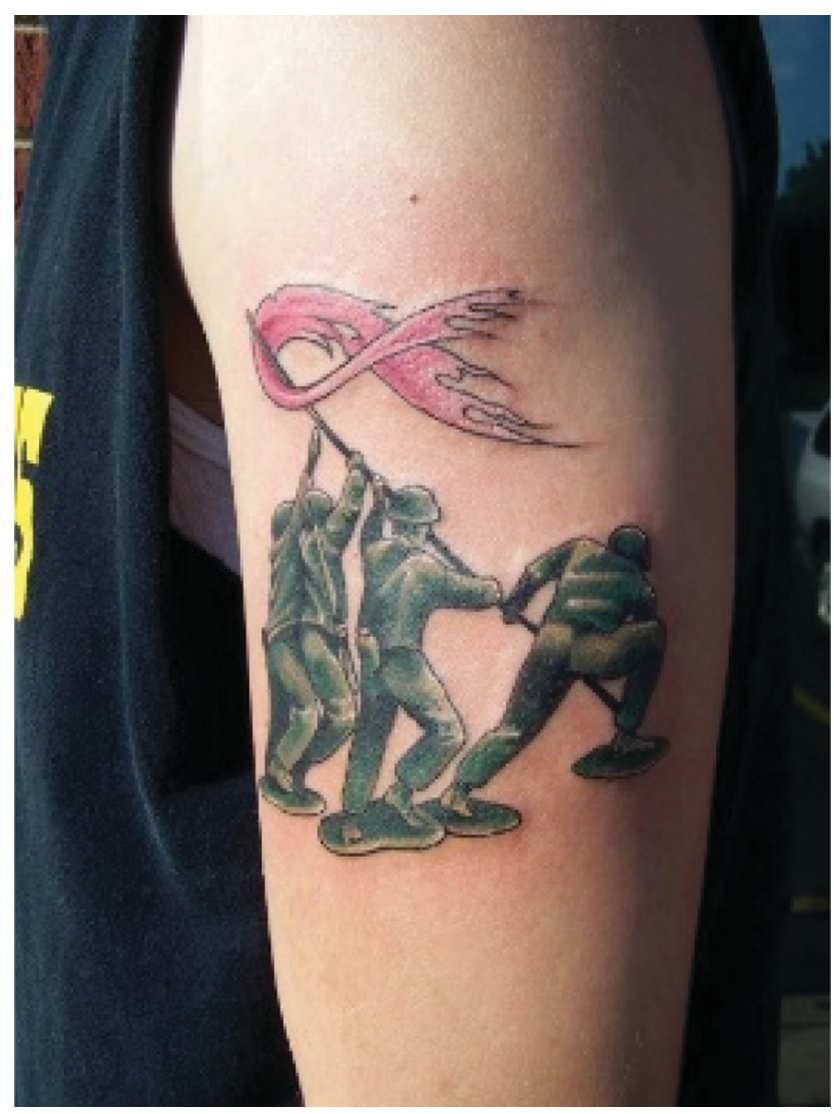

Figure 3: Breast cancer tattoo (BC29).

https:/ / www.pinterest.co.uk/pin/544091198702102630, accessed 31 March 2019

Multimodal metaphors of VIOLENCE - but not WAR - are realised in combinations of the lexemes 'fight' and 'kick' with an image of boxing gloves (BC8, BC9, BC13, ED7). ${ }^{6}$

An interesting extension of the violence domain is seen in the word 'fuck', also realised as ' $\mathrm{f}^{*} \#^{\prime}$, as used in breast cancer tattoos. It sexualises the violence source domain, but in one case co-occurs with the image of a woman making a fist, which we interpret as adding the notion of physical strength rather than referencing fisting as a sexual practice (see Figure 4). 


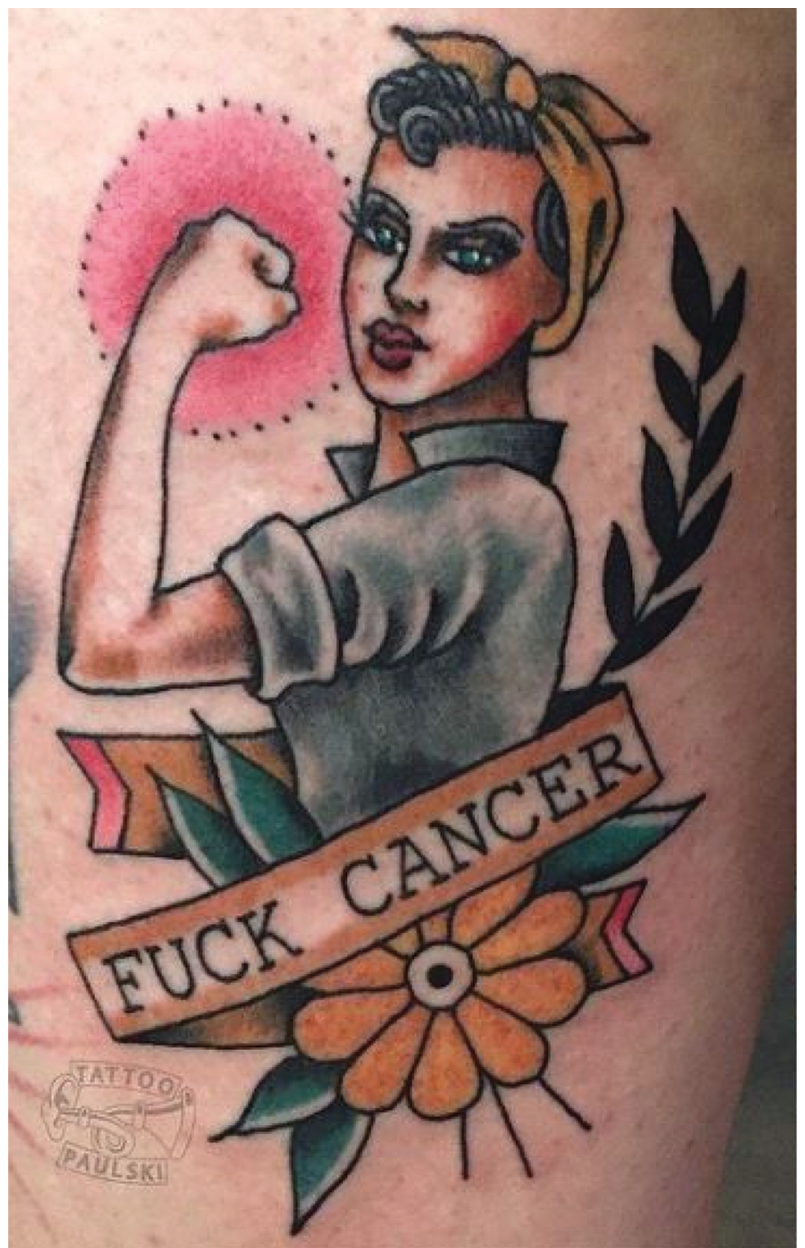

Figure 4: Breast cancer tattoo (BC3).

https://www.instagram.com/p/BNDCOa_Bvk2/?taken-by=karenlazarovitz_brca, accessed 31 March 2019

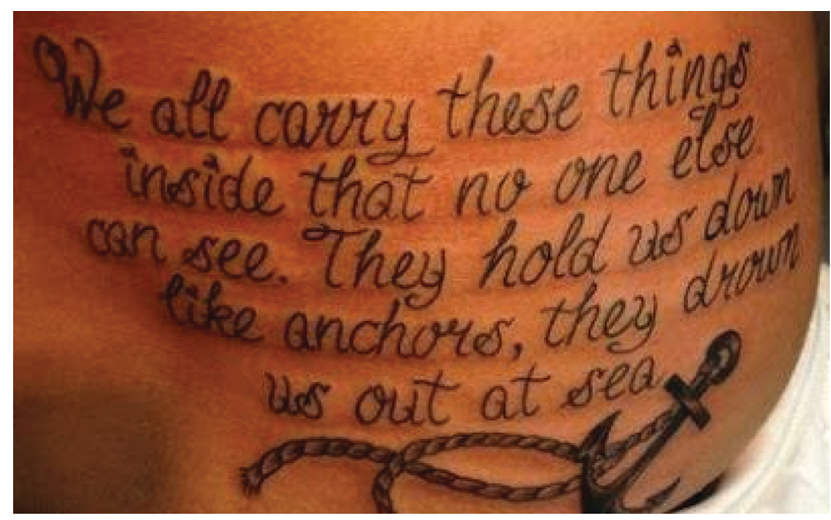

Figure 5: Song lyrics from ‘Chelsea Smile' (ED1).

https:/ / www.azlyrics.com/lyrics/bringmethehorizon/chelseasmile.html, accessed 31 March 2019

The tattoo alludes to the wartime posted We Can Do It!, which was originally produced by J. Howard Miller in 1943 and intended as an inspirational image aimed at boosting worker morale during WW2. It was later rediscovered and used by feminists as a symbol of female empowerment (Kimble and Olson 2006), with the slogan conveying confidence, while the first person plural connotes solidarity. The intertextuality thus backgrounds the aspect of sexual violence and foregrounds a dismissal of cancer as a personified adversary. Interestingly, the fist in the tattoo is surrounded by a pink circle, which could either reference femininity or recall the male comic book superhero Ironfist. Finally, the poster's wartime origin additionally conjures up the source domain of war.

VIOLENCE and WAR metaphors are culturally connoted as masculine. Masculinity is also expressed in the angular, straight, unconnected fonts that are used when lexemes involve verbal aggression and swearing at a personified cancer. This culturally masculine font is also used with images referring to warfare, such as writing 
on dog tags. More often, however, the expression of culturally masculine metaphors in the tattoos is feminised. For example, boxing gloves may be combined with a pink woman sign (ED23), which integrates a stereotypically feminine colour with a symbol that carries connotations of strong womanhood, if not feminism. Also, the word 'fight' is more often than not found as part of the clause 'fight like a girl' (BC8, BC9, ED7), where the word 'girl' is written in a sloped, curved and connected font, which can be read as culturally feminine. In addition, the slogan is sometimes placed alongside the pink ribbon or pink boxing gloves. Initially a derogatory classification, 'fight like a girl' has been re-appropriated and achieved the status of a cultural meme. As such, it is found in the title of several albums by female artists (e. g. Autumn 2012), a documentary about women boxers (Morley 2013) and a number of books on feminism (e. g. Ford 2016). More traditional femininity is expressed alongside the VIOLENCE when the phrase 'fight like a girl' is not only combined with boxing gloves but additionally with a butterfly (BC9) or when the word 'fighter' sits alongside the image of a flower (ED8). A butterfly symbolises not only transformation ${ }^{7}$ but also fragility, a feature that it shares with flowers.

It is noteworthy that in the endometriosis tattoos, flower images often show plants that can cause pain, e. g. roses with prominent thorns, or thistles. This indicates the other prominent identity constructed by the tattoos, namely that of the wearer as a sufferer.

\section{Sufferers}

Both breast cancer and endometriosis entail suffering. That suffering is physical, brought about by debilitating pain and, in the case of cancer, the side effects of treatment as well. Suffering is also mental: while breast cancer has very good survival rates if detected early enough (see introduction), it is still a potentially life-shortening disease and as such triggers strong emotions. Endometriosis, although not fatal, can currently not be cured, which raises the prospect of decades of suffering, often in the face of one's pain being downplayed and the condition remaining undiagnosed.

It is therefore noteworthy that where tattoos construct the wearer as a sufferer, it is mostly as a hopeful one. Hope as an abstract concept is less easy to visualise than metaphorical identities as a fighter or warrior and we therefore find monomodal lexical expressions of the identity: by the word 'hope' (ED10) or by a combination of the lexemes 'faith, hope, love, life' (BC7) in a possible intertextual reference to 1 Corinthians 13:13 ('But now these three things abide: faith, hope, love'). Hope is also implied by the negation 'no fear' (ED5). Multimodally, 'hope' is combined with a butterfly as a symbol of transformation towards something beautiful (BC12; BC23 and ED24 are similar, although monomodal, tattoos featuring only a ribbon and a butterfly). The same idea of change for the better can also be expressed lexically, through the phrase 'semper ad meliora' ('always toward better things', BC6), or by the word 'believe' (BC5), which is related to the mental state of hopefulness. Visually, positive transformation is expressed by the integrated image of a feather dissolving into flying birds (BC21, ED22; see Figure 1); here, the disease is constructed as a lack of freedom that the tattoo wearer hopes to overcome.

In some cases, it is only the wearer's comments on the tattoo that show what identity it constructs. ED21 is an interesting case of symbolism combining an owl, a blue lotus blossom, barbed wire, blood and the yellow ribbon for endometriosis. In an explanation of the tattoo, its wearer reports that the combination of the symbolic elements she chose to have in the tattoo stand for wisdom, transformation, pain and endurance. Her posting of the image has by the caption 'I will endure. I will flourish. And I am still beautiful!'. Through this tattoo, the wearer therefore constructs an agentive, tenacious and positive identity that conforms to both traditional femininity ('beautiful') as well as expressing endurance. Similarly, the image of a thistle tattoo (ED4) was posted on Instagram with an intertextual quote from 2 Corinthians 12:7-9 referring to pain, weakness and suffering ${ }^{8}$ along with an explanation of the healing properties of the milk thistle, which again introduces the concept of hope. Finally, some tattoos show the image of an anchor, a Christian symbol of hope (Klöpping 2012). That this feature constructs the wearer as a sufferer who has, or wishes to have, hope is in one instance corroborated by the wearer explaining that she is 'an endowarrior, struggling with this disease and infertility. I need some hope' (ED20).

Both breast cancer and endometriosis tattoos make frequent use of the lexemes 'strength' and 'strong'. These can take the form of self-directed imperatives, where the wearer requests herself to 'stay strong' (ED16). Endometriosis tattoos also often feature the phrase 'through pain comes strength', which again expresses the idea that suffering can be transformative and lead to something positive. One breast cancer tattoo (BC16) incorporates another intertextual quote from the Bible, namely the extract 'be strong and courageous' from Joshua 1:9 ('Have I not commanded you? Be strong and courageous. Do not be afraid; do not be discouraged, for the Lord your God will be with you wherever you go'). Sometimes though, the woman living with breast cancer simply refers to herself as a literal survivor (BC17), which, in the face of a potentially fatal disease, can be seen as expressing strength and hope in itself. 
The above analysis has shown that the identity of a hopeful sufferer is often couched in religious terms. This is also the case in images of a rosary or praying hands $(\mathrm{BC} 1, \mathrm{BC} 30)$, while images of the Christian cross combined or integrated with a ribbon (BC24, BC25, ED25) evoke the phrase 'a cross to bear', which is indeed the caption to a posting of a tattoo image (ED25). We here see a shift in discourse from restitutive to palliative, as the disease is constructed as a heavy burden. At the same time, the identity of the sufferer contrasts with dominant discourses of wellbeing, agency and positive attitudes. While religious women may find strength and power in accepting their 'cross', such acceptance of suffering could also be seen as constructing identities that are in alignment with traditional discourses of womanhood and pain. This identity construction is much less frequent though (five cases only) and mostly found in the breast cancer tattoos. This may be due to the potentially terminal nature of the disease, with wearers deriving not only strength and hope from their faith, but also solace in the face of the seemingly inevitable.

\section{Subversive identities: despair and rationality}

The above analysis has established that breast cancer and endometriosis tattoos construct two main identities for their wearers: that of a fighter or warrior and that of a sufferer. However, two tattoos in our sample do not seem to fit either mould but express different identities. The first is an endometriosis tattoo that consists of an intertextual quote from the 2008 song 'Chelsea Smile' by heavy metal band Bring Me the Horizon. The song is characterised by emphatic beats, high-volume guitars and half sung, half screamed lyrics about disease ('This disease is getting worse./I counted my blessings, now I'll count this curse'), religion, and feelings of guilt and regret. The music and lyrics combine into a multimodal artefact that expresses aggression and despair. The tattoo recontextualises the song to make reference to the invisibility of endometriosis and the isolation that it causes for women who live with it. We can see this tattoo as an example of how such artefacts "are made not only as strategies for making meaning and reaching out to others similarly situated, but also in anger and indignation" (Radley and Bell 2011: 219).

The word 'anchors' is also visually represented, but here reverses the symbolic meaning of hope into an expression of suffering that is angry and desperate. The tattoo constructs its wearer as 'tarrying with grief [and] remaining exposed to its unbearability' (Butler 2004: 30). Set against a dominant discourse of women with illness as either agentive and aggressive, or at least hopeful, this tattoo can be said to provide a subversive identity.

One of the breast cancer tattoos in the sample (BC2) takes a different but equally subversive approach, featuring as it does the chemical formula for Herceptin, the brand name for the Trastuzumab antibody used to treat breast cancer. In her comment next to the image of the tattoo, the wearer expresses her resistance against the pink ribbon as a symbol of breast cancer ('I am not a pink ribbon kind of girl - I'm actually quite against it') and states that she had the tattoo made 'to commemorate my journey' as a woman living with breast cancer.

While the JOURNEY metaphor is a staple of discourse on cancer (Semino et al. 2017a), the chemical formula provides a space for rationalisation. Through the reference to a scientific element, the tattoo allows the wearer to resist dominant discourses of both traditional femininity - as manifested in the pink ribbon - and of either fighter or sufferer.

\section{Conclusion}

In this paper we set out to investigate the forms and functions of tattoos worn by women who live with breast cancer or endometriosis. Our findings show that, despite the different levels of public awareness of the respective conditions, tattoos worn by women who live with them serve to construct similar identities for both the disease and for the woman. Both breast cancer and endometriosis are predominantly seen as a metaphorical enemy that is fought by the woman living with the condition. Such a fighter or warrior identity aligns with sociocultural, even moral imperatives to 'stay strong' and be agentive in the face of illness. The identity as a hopeful sufferer, while less aggressive, instantiates the same discourse of positivity. The request to 'think positive' is sometimes resisted by women living with breast cancer (Wilkinson and Kitzinger 2000), not least because it can shift the responsibility for successful treatment onto the patient. Our findings show that alternatives are limited to subversive identities built on either anger and despair, or on rationality. It seems that the complexity and variability of feelings and mental states that living with serious medical conditions brings with it do not lend themselves to a single, permanent tattoo. The tattoo wearers in our data have mostly chosen to have a tattoo that represents their predominant identity in the face of their disease, but it would be interesting to see if some women have multiple tattoos constructing different identities. 
Further studies involving interviews with women with both conditions would provide interesting perspectives on women's own experiences and the various identities found as well as inform the discussion surrounding awareness. In fact, studies of accounts of endometriosis experiences using interview data (e. g. Bullo 2018) have found that the fighter identity is mostly associated with the difficulties in achieving a diagnosis and the perceived 'battle' against pain normalisation and dismissal that women reportedly go through before being diagnosed with endometriosis. Interestingly, further studies of endometriosis pain accounts using similar type of data show that women feel subdued by pain, aligning these participants with the sufferer identity identified earlier (Bullo 2019).

Other research building on the present study could address the interpersonal function of tattoos, and of posting images of them on social media. This could for instance be done by a systematic analysis of comments and interactions around tattoos, or by an analysis of online forum data on breast cancer and endometriosis to complement the present focus on visually oriented online platforms. Finally, we believe that our study supplements previous research (e. g. Semino et al. 2017b) that recommends using visual artefacts in medical consultations, be those existing works of art (quoted in Fulgenz 2018), patients' artwork or indeed their tattoos.

\section{Appendix}

Table 1: Tattoo descriptors.

\begin{tabular}{|c|c|c|c|c|c|}
\hline & Ribbon & Lexeme(s) & Image(s) & Type font & Intertextuality \\
\hline $\mathrm{BC} 1$ & & & rosary & & \\
\hline BC2 & & & chemical formula & straight unconnected angular & \\
\hline BC3 & & 'fuck' & & straight unconnected angular & WW2 poster \\
\hline BC4 & Pink & 'battle' & butterfly & sloped connected curved & \\
\hline BC5 & Pink & 'believe' & star & sloped connected curved & \\
\hline BC6 & Pink & 'better' (Latin) & & sloped connected curved & \\
\hline $\mathrm{BC} 7$ & Pink & $\begin{array}{l}\text { 'faith-hope-live- } \\
\text { love' }\end{array}$ & & sloped unconnected curved & \\
\hline $\mathrm{BC} 8$ & Pink & 'fight-girl' & boxing glove & $\begin{array}{l}\text { sloped-straight connected } \\
\text { curved-angular }\end{array}$ & \\
\hline BC9 & Pink & 'fight-girl' & $\begin{array}{l}\text { boxing gloves, } \\
\text { butterfly }\end{array}$ & sloped connected curved & \\
\hline BC10 & Pink & 'fighter' & & sloped connected curved & \\
\hline BC11 & Pink & 'fuck' & & straight unconnected angular & \\
\hline BC12 & Pink & ‘hope' & butterfly & sloped connected curved & \\
\hline $\mathrm{BC} 13$ & Pink & 'kick' & boxing glove & straight unconnected angular & \\
\hline BC14 & Pink & 'love' (Chinese) & key & & \\
\hline BC15 & Pink & $\begin{array}{l}\text { 'strength' } \\
\text { (Japanese) }\end{array}$ & flower & & \\
\hline BC16 & Pink & $\begin{array}{l}\text { 'strong- } \\
\text { courageous' }\end{array}$ & & sloped connected curved & bible quote \\
\hline BC17 & Pink & 'survivor' & & sloped connected curved & \\
\hline BC18 & Pink & & anchor & & \\
\hline BC19 & Pink & & anchor, flower & & \\
\hline BC20 & Pink & & bird & & \\
\hline BC21 & Pink & & bird, feather & & \\
\hline $\mathrm{BC} 22$ & Pink & & boxing gloves & & \\
\hline $\mathrm{BC} 23$ & Pink & & butterfly & & \\
\hline BC24 & Pink & & cross & & \\
\hline BC25 & Pink & & cross & sloped connected curved & \\
\hline BC26 & Pink & & dog tag & straight unconnected angular & \\
\hline BC27 & Pink & & flower & & \\
\hline BC28 & Pink & & flower, heart & & \\
\hline BC29 & Pink & & & & Iwo Jima photo \\
\hline BC30 & Pink & & praying hands & & \\
\hline BC31 & Pink & & wings & & \\
\hline ED1 & & 'anchor' & anchor & sloped connected curved & song lyrics \\
\hline ED2 & & 'hero' & flower & sloped unconnected angular & \\
\hline ED3 & & 'pain-strength' & & sloped connected curved & \\
\hline
\end{tabular}




\begin{tabular}{|c|c|c|c|c|}
\hline ED4 & & & flower & \\
\hline ED5 & Yellow & & 'fear' & sloped connected curved \\
\hline ED6 & Black & 'fight' & & sloped connected curved \\
\hline ED7 & Yellow & 'fight-girl' & boxing glove & sloped unconnected curved \\
\hline ED8 & Yellow & 'fighter' & flower & sloped connected curved \\
\hline ED9 & Yellow & 'fighter' & & sloped connected curved \\
\hline ED10 & Yellow & 'hope' & & sloped connected curved \\
\hline ED11 & Yellow & 'pain-strength' & boxing gloves & sloped connected curved \\
\hline ED12 & Yellow & 'pain-strength' & butterfly & straight connected curved \\
\hline ED13 & Yellow & 'pain-strength' & spoon & sloped unconnected curved \\
\hline ED14 & Yellow & 'strength' & flower & sloped connected curved \\
\hline ED15 & Yellow & 'strength' & flower, heart & sloped connected curved \\
\hline ED16 & Yellow & 'strong' & & sloped connected curved \\
\hline ED17 & $\begin{array}{l}\text { Black and } \\
\text { Teal }\end{array}$ & 'visible' & $\begin{array}{l}\text { barbed wire, } \\
\text { butterfly, flower }\end{array}$ & sloped connected curved \\
\hline ED18 & Yellow & 'visible' & butterfly & sloped connected curved \\
\hline ED19 & Yellow & 'warrior' & & sloped connected curved \\
\hline ED20 & Yellow & & anchor, flower & \\
\hline ED21 & Yellow & & $\begin{array}{l}\text { barbed wire, bird, } \\
\text { flower }\end{array}$ & \\
\hline ED22 & Yellow & & bird, feather & \\
\hline ED23 & Yellow & & $\begin{array}{l}\text { boxing glove, woman } \\
\text { sign }\end{array}$ & \\
\hline ED24 & Yellow & & butterfly & \\
\hline ED25 & Yellow & & cross & \\
\hline ED26 & Yellow & & dog tag & straight unconnected angular \\
\hline ED27 & Yellow & & flower & \\
\hline ED28 & Yellow & & woman sign & \\
\hline ED29 & Yellow & & & \\
\hline
\end{tabular}

\section{Notes}

1 ED stands for 'endometriosis' and BC for 'breast cancer', while the numbers are the running number for the tattoos. See Table 1 in the Appendix for the full list of descriptors.

2 In May 2018, tattoos were banned on Chinese television as vulgar and morally dubious (Quackenbush and Chen 2018).

3 Thanks are due to Xiaoxi Wu and Liesa Takagi for the translations.

․ 4 One case (BC8) featured two words in different type fonts, both of which therefore became part of the descriptor.

5 In accordance with the conventions of conceptual metaphor theory, metaphors are indicated by small capitals.

6 The lexemes ' $\mathrm{kick}^{\prime}$ and 'fuck' (see below) have also been realised visually in tattoos, although our sample does not include any instances. For examples, see https://aheartyme.files.wordpress.com $/ 2015 / 10 / \mathrm{k} 61 . \mathrm{png}$ ? w $=558$ and https://cdn.shopify.com/s/files/1/0955/5840/products/FullSizeRender_91_2048x@2x.jpg?v=1476934706 (both accessed May 26, 2018).

7 Butterflies as symbols of transformation also feature in tattoos done on the chest after mastectomy and, in a different context, as tattoos on scars from domestic violence (Schnitzler 2017).

8 The passage from the Bible reads: 'Therefore, in order to keep me from becoming conceited, I was given a thorn in my flesh, a messenger of Satan, to torment me. Three times I pleaded with the Lord to take it away from me. But he said to me, "My grace is sufficient for you, for my power is made perfect in weakness." Therefore I will boast all the more gladly about my weaknesses, so that Christ's power may rest on me.'

\section{References}

Al Zidjaly, N. (2011). Multimodal texts as mediated actions: Voice, synchronization and layered simultaneity in images of disability. In: Multimodality in Practice: Investigating Theory in Practice through Methodology, S. Norris (Ed.), 190-205. London: Routledge.

Arruda, M. A. Z., Petta, C. A., Abrão, M. S., and Benetti-Pinto, C. L. (2003). Time elapsed from onset of symptoms to diagnosis of endometriosis in a cohort study of Brazilian women. Human Reproduction, 18(4):756-759.

Atkinson, M. (2003). Tattooed: The Sociogenesis of Body Art. Toronto: University of Toronto Press.

Autumn, E. (2012). Fight Like a Cirl. The Asylum Emporium.

Bell, S. E. (2006). Living with breast cancer in text and image: Making art to make sense. Qualitative Research in Psychology, 3:31-44.

Benwell, B., and Stokoe, E. (2006). Discourse and Identity. Edinburgh: Edinburgh University Press.

The Breast Cancer Fund, The American Cancer Society and The Susan C. Komen Breast Cancer Foundation. (1998). Art. Rage. Us: Art and Writing by Women with Breast Cancer. San Francisco: Chronicle Books.

Bullo, S. (2014). Evaluation in Advertising Reception: A Socio-Cognitive and Linguistic Perspective. Basingstoke: Palgrave Macmillan. 
Bullo, S. (2018). Exploring disempowerment in women's accounts of endometriosis experiences. Discourse \& Communication, 11(6):569-586. Bullo, S. (2019). "I feel like I'm being stabbed by a thousand tiny men": The challenges of communicating endometriosis pain. Health. https://doi.org/10.1177/1363459318817943.

Butler, J. (2004). Precarious Life: The Powers of Mourning and Violence. London: Verso.

Cancer Research UK (2017). Breast cancer: Survival. Available at http://www.cancerresearchuk.org/about-cancer/breast-cancer/survival (accessed May 26, 2017).

Culley, L., Law, C., Hudson, N., Denny, E., Mitchell, H., Baumgarten, M., and Raine-Fenning, N. (2013). The social and psychological impact of endometriosis on women's lives: A critical narrative review. Human Reproduction Update, 19(6):625-639.

Dann, C., Callaghan, J., and Fellin, L. (2016). Tattooed female bodies: Considerations from the literature. Psychology of Women Section Review, 18(1):43-51.

Darling, R. (2017). Ellie Kammer: Endometriosis in Art. Available at http://www.thisisradelaide.com.au/radlife/2017/6/26/n28qzxt1pbdcvyxu2gxghj2np23vqr (accessed May 26, 2018).

De Graaff, A. M., D'Hooghe, T. M., Dunselman, G. A. J., Dirksen, C. D., and Hummelshoj, L., WERF EndoCost Consortium, ... and Wullschleger, Martin E. (2013). The significant effect of endometriosis on physical, mental and social wellbeing: results from an international crosssectional survey. Human Reproduction, 28(10):2677-2685.

DeMello, M. (2000). Bodies of Inscription: A Cultural History of the Modern Tattoo Community. Durham: Duke University Press.

The Economist (2014). Inked in: Has the tattooing frenzy peaked? Available at https://www.economist.com/news/britain/21627663-hastattooing-frenzy-peaked-inked (accessed May 26, 2017).

Edgerton, R. B., and Dingman, H. F. (1963). Tattooing and identity. International Journal of Social Psychiatry, 9(2):143-153.

Fairclough, N. (2003). Researching Discourse: Textual Analysis for Social Research. London: Routledge.

Flusberg, S. J., Matlock, T., and Thibodeau, P. H. (2018). War metaphors inpublic discourse. Metaphor and Symbol, 33(1):1-18.

Forceville, C., and Urios-Aparisi, E. (2009). Multimodal Metaphor. Berlin: de Gruyter.

Ford, C. (2016). Fight Like a Girl. London: Oneworld Publications.

Fulgenz, K. (2018). Portrait pain scale. Tweet, 6 June. Available at https://twitter.com/KatbeeFulgenz/status/1004572494907359232 (accessed June 10, 2016).

Halliday, M. A. K. (1978). Language as Social Semiotic: The Social Interpretation of Language and Meaning. London: Edward Arnold.

Hinde, N. (2017). Selfless cosmetic tattoo artist inks 3D nipples onto cancer survivors for free. HuffPost UK. Available at http://www.huffingtonpost.co.uk/entry/permanent-makeup-by-claire-louise-3d-nipples-for-cancer-survivors-free-ofcharge_uk_58e39a22e4bof4a923b1d213 (accessed May 26, 2018).

Kang, M., and Jones, K. (2007). Why do people get tattoos?. Contexts, 6(1):42-47.

Kimble, J. J., and Olson, L. C. (2006). Visual rhetoric representing Rosie the Riveter: Myth and misconception in J. Howard Miller's 'We Can Do It!' poster. Rhetoric and Public Affairs, 9(4):533-569.

King, S. (2006). Pink Ribbons, Inc.: Breast Cancer and the Politics of Philanthropy. Minneapolis: University of Minnesota Press.

Klöpping, L. (2012). Customs, Habits and Symbols of the Protestant Religion. Norderstedt: GRIN Verlag.

Kress, G., and van Leeuwen, T. (2006). Reading Images: The Grammar of Visual Design. 2nd Edition. London: Routledge.

Kristeva, J., and Moi, T. (1986). The Kristeva Reader. Oxford: Basil Blackwell.

Kronfeld, H. (2018). How did endo awareness month begin? Five fast facts. Available at https://www.endofound.org/how-did-endoawareness-month-begin-five-fast-facts (accessed June 10, 2018).

Langman, L. (2008). Punk, porn and resistance: Carnivalisation and the body in popular culture. Current Sociology, 56(4):657-677.

Martin, C. W. (2013). Tattoos as narratives: Skin and self. The Public Journal of Semiotics, IV(2):2-46.

Morley, J. (2013). Fight Like a Girl. Vision Films.

Norris, S. (2004). Analyzing multimodal interaction: A methodological framework. London: Routledge.

Norris, S., and Makboon, B. (2015). Objects, frozen actions, and identity: A multimodal (inter)action analysis. Multimodal Communication, 4(1):43-59.

O'Halloran, K. L. (2008). Systemic functional-multimodal discourse analysis (SF-MDA): Constructing ideational meaning using language and visual imagery. Visual Communication, 7(4):443-475.

Office for National Statistics (2018). Cancer registration statistics, England: First release, 2016. Available at https://www.ons.gov.uk/peoplepopulationandcommunity/healthandsocialcare/conditionsanddiseases/bulletins/cancerregistrationstatisticsengland/2016 (accessed May 26, 2018).

Pitts, V. (2004). Illness and internet empowerment: Writing and reading breast cancer in cyber-space. Health, 8:33-59.

Pragglejaz Group. (2007). MIP: A method for identifying metaphorically used words in discourse. Metaphor and Symbol, $22(1): 1-39$.

Quackenbush, C., and Chen, A. H. (2018). 'Tasteless, vulgar and obscene': China just banned hip-hop culture and tattoos from television. Time, 22 January. Available at http://time.com/5112061/china-hip-hop-ban-tattoos-television/(accessed May 15, 2018).

Radley, A. (2002). Portrayals of suffering: On looking away, looking at, and the comprehension of illness experience. Body and Society, 8:1-23.

Radley, A., and Bell, S. E. (2007). Artworks, collective experience and claims for social justice: The case of women living with breast cancer. Sociology of Health \& Illness, 29(3):366-390. doi:10.1111/j.1467-9566.2007.00499.x.

Radley, A., and Bell, S. E. (2011). Another way of knowing: Art, disease and illness experience. Health, 15(3):219-222.

Schnitzler, M. (2017). Zhenya Zakhar verwandelt Narben häuslicher Gewalt in Kunstwerke. Brigitte, 23:7.

Semino, E., Demmen, J., Demjén, Z., Koller, V., Payne, S., Hardie, A., and Rayson, P. (2017a). The online use of Violence and Journey metaphors by cancer patients, as compared with health professionals: A mixed methods study. British Medical Journal: Supportive and Palliative Care, 7:60-66.

Semino, E., Zkrzewska, J. M., and Williams, A. (2017b). The art of medicine:Images and the dynamics of pain consultations. The Lancet 389(10075):1186-1187.

Sjoholm, B. (Ed.). (2016). So Much to Be Done: The Writings of Breast Cancer Activist Barbara Brenner. Minneapolis: University of Minnesota Press. 
van Leeuwen, T. (2006). Towards a semiotics of typography. Information Design Journal, 14(2):139-155.

Wilkinson, S., and Kitzinger, C. (2000). Thinking differently about thinking positive: A discursive approach to cancer patients' talk. Social Science \& Medicine, 50(6):797-811.

\section{Bionotes}

Stella Bullo is a senior lecturer in Linguistics at Manchester Metropolitan University. Her research is in the area of socio-cognitive discourse analysis. Her current research is in the area of health and clinical communication investigating pain and discourses of gynaecological conditions, and endometriosis in particular, and cross-cultural discourses of health. 